\title{
DA INTEGRAÇÃO À INCLUSÃO SOCIAL: 0 ESTATUTO DAS PESSOAS COM DEFICIÊNCIA E A CONCRETIZAÇÃO DA INCLUSÃO PELOS DIREITOS ASSEGURADOS
}

\author{
Renata Salgado Leme \\ Doutora em Filosofia e Teoria Geral do Direito pela \\ Universidade de São Paulo (USP). Professora titular dos \\ cursos de Graduação e Pós-Graduação da Faculdade de \\ Direito da Universidade de Santa Cecília (UNISANTA). \\ Advogada. \\ renataleme@aasp.org.br \\ Samira da Costa Fontes \\ Mestranda em Direito da Saúde UNISANTA. Advogada. \\ Membro da Comissão de Direito da Saúde da OAB/Santos. \\ samirafontes@hotmail.com
}

\begin{abstract}
RESUMO: O movimento de emancipação das pessoas com deficiência passou por diversas fases, começando pela exclusão, depois segregação, integração social e, por fim, inclusão social. A ideia central deste trabalho é, após percorrer as fases históricas, chegar ao atual modelo de inclusão social, demonstrando a evolução conquistada pelo Brasil com a edição da nova Lei de Inclusão das Pessoas com Deficiência, também chamada de Estatuto das Pessoas com Deficiência (Lei $\left.n^{\circ} 13.146 / 2015\right)$. Destacou-se que diversos dos direitos previstos nesta Lei possibilitam a realização da inclusão de maneira concreta, a fim de que efetivamente se rompam todas as barreiras que impedem a interação das pessoas com deficiência à sociedade global.
\end{abstract}

PALAVRAS-CHAVE: Deficiência; Acessibilidade; Saúde; Trabalho; Cidadania.

From integration to social inclusion: the Status of People with Disabilities and the realization of the inclusion by the assured rights

ABSTRACT: The emancipation movement of people with disabilities went through several phases, starting with exclusion, then segregation, social integration, and finally social inclusion. The central idea of this work is, after going through the historical phases, up to the current model of social inclusion, to demonstrate the evolution achieved in Brazil with the new Law on the Inclusion of People with Disabilities, also called the Statute of People with Disabilities (Law 13.146/2015). We adopted documentary and bibliographic research and historical-comparative analysis. Thus, it is presented how several of the rights provided for in the law effectively turn inclusion into something concrete, so that effectively all barriers that prevent the interaction of people with disabilities with the whole of society can be broken.

KEYWORDS: Disabled; Accessibility; Health; Work; Citizenship. 
Da integração à inclusão social: o Estatuto das Pessoas com Deficiência e a concretização da inclusão pelos direitos assegurados

\section{INTRODUÇÃO}

Sempre houve na sociedade um expressivo contingente de pessoas com limitações de ordem física, mental, sensorial ou intelectual e, aos membros dessa coletividade, nem sempre se reconheceu a condição de "sujeitos de direitos iguais" atribuída aos demais seres humanos. A História é marcada por preconceitos, exclusão e segregação social dos indivíduos que integram esse grupo. Mas, sem dúvida, a humanidade vem avançando e, na atualidade, observa-se uma maior conscientização sobre a urgência em reconhecer e respeitar essas pessoas.

O presente estudo é de cunho teórico, segue o método dedutivo, o procedimento de pesquisa bibliográfico e adota uma abordagem qualitativa, entendendo ser a forma adequada para se compreender a natureza do fenômeno social investigado.

Ademais, o trabalho busca analisar o tema a partir da perspectiva histórica, utilizando como fontes bibliográficas SILVA (1987), FIGUEIRA (2008), GARCIA (2011), GUGEL (2016) e MAIOR (2016).

O texto também pretende evidenciar o processo de inserção social e de emancipação das pessoas com deficiência, destacando a análise dos modelos da exclusão, segregação, integração e inclusão deste grupo social.

Os conceitos exclusão e segregação serão utilizados na acepção de FIGUEIRA (2008), ou seja, o termo exclusão considera a pessoa deficiente como inválida e inútil para a sociedade e a expressão segregação considera o deficiente como ser inferior, portanto, discriminado pela coletividade.

Os conceitos integração e inclusão serão usados na acepção de SASSAKI (2006), isto é, a integração para indicar que a comunidade permanece estática, cabendo ao deficiente se adaptar à mesma e pelo prisma da inclusão a sociedade assume uma postura dinâmica, devendo promover mudanças culturais, sociais, espaciais etc., a fim de atender as reais necessidades destas pessoas.

No caminhar investigativo aqui delineado, busca-se demonstrar a mudança de consciência da sociedade a respeito das pessoas com deficiência, após a era das Convenções Internacionais de Direitos Humanos. Nesses novos tempos, não se exige que o deficiente se adapte aos modelos impostos pela sociedade, mas que parta da sociedade o ajuste, a promoção de adequações e a eliminação das barreiras que impeçam o exercício de direitos por esse universo de pessoas.

Procura-se demonstrar o grande avanço brasileiro a partir da publicação da Lei 13.146, em 6 de julho de 2015, conhecida como "Estatuto das Pessoas com Deficiência" ou "Lei Brasileira de Inclusão da Pessoa com Deficiência", que abarcou em seu título e em diversos dispositivos a expressão "inclusão". Com isso, o objetivo deste trabalho é demonstrar como os direitos assegurados na Lei de Inclusão devem ser concretizados.

Com a criação de Tratados Internacionais e de novos diplomas normativos, espera-se que a sociedade se sensibilize e mude sua concepção, a partir da consolidação de uma consciência coletiva que valorize a importância da proteção desses direitos, buscando concretizá-los para que não fiquem apenas listados de forma genérica e abstrata. Afinal, a população com deficiência no Brasil tem aumentado por diversas razões, tais como: subdesenvolvimento social e econômico, aspectos ambientais, pessoais e de trabalho, além do aumento da expectativa de vida, já que a deficiência não é apenas congênita, mas também pode ser adquirida. 
Segundo dados do Instituto Brasileiro de Geografia e Estatística (IBGE) de 2010, mais de 45,6 milhões de brasileiros declararam ter alguma deficiência, representando $23,9 \%$ da população do país.

Cada vez mais a coletividade passa a ter contato com pessoas que possuem algum tipo de limitação ou restrição. Isso demonstra que o assunto precisa ser amplamente debatido e que melhorias, por meio da promoção de políticas públicas inclusivas, precisam ser urgentemente efetivadas. Ademais, nenhuma lei, serviço, estratégia, benefício ou programa deve ser executado sem a participação das próprias pessoas com deficiência, pois se elas são "sujeitos de direitos", iguais a todos, sua opinião deve ser sempre considerada.

\title{
1 HISTÓRIA E EVOLUÇÃO DO TRATAMENTO DADO ÀS PESSOAS COM DEFICIÊNCIA
}

Como já foi dito, a humanidade sempre conviveu com pessoas que tinham certas limitações, seja de ordem física, mental, sensorial ou intelectual. Apesar disso, conquistas na seara dos direitos das pessoas com deficiência só foram alcançadas em período muito recente. Infelizmente, essas pessoas não eram reconhecidas como "sujeitos de direitos", já que não opinavam e nem decidiam sobre as suas vidas.

Interessante é a divisão feita por SASSAKI (2011, p. 2) quanto às práticas sociais em relação às pessoas com deficiência. $\mathrm{O}$ autor divide-as em quatro eras: exclusão (antiguidade até o início do século 20), segregação (década de 20 até 40), integração (década de 50 até 80 ) e inclusão (décadas de 90 até as próximas décadas do século 21).

O modelo de exclusão era predominante na Antiguidade e na Alta Idade Média. Conforme Gugel, a conclusão dos estudiosos quanto ao tema é no sentido de que, na concepção das sociedades existentes à época, o indivíduo deficiente significava um fardo para a comunidade, tanto que certas tribos se desfaziam de crianças detentoras de tais condições.

Em Esparta, por exemplo, por volta de 480 a. C., crianças recém-nascidas frágeis ou com alguma deficiência eram jogadas do alto do monte Taigeto, há mais de 2.400 metros de altura, por não estarem dentro do padrão físico adequado (SULLIVAN, 2001, p. 262-266 apud LOPES).

A civilização romana, por sua vez, como preconizava a perfeição e a estética corporal, tinha a deficiência como monstruosidade, o que legitimava atos seletivos. Nesse sentido, afirma Otto Marques da Silva (1997, p. 127-129):

\begin{abstract}
No Direito Romano havia leis que se referiam ao reconhecimento dos direitos de um recém-nascido e em quais circunstâncias esses direitos deveriam ser garantidos ou poderiam ser negados. A vitalidade e a forma humana eram condições essenciais. Estava permitida a morte intencional de qualquer criança abaixo dos três anos de idade quando tivesse nascida mutilada ou fosse considerada como monstruosa. Nestes casos, a lei previa a morte ao nascer. Na sequência, o autor expõe um trecho do famoso discurso de Sêneca (4-65 d. C) que justifica o infanticídio: 'Não se sente ira contra um membro gangrenado que se manda amputar; não o cortamos por ressentimento, pois, trata-se de um rigor salutar. Matam-se cães quando estão com raiva; exterminam-se touros bravios; cortam-se as cabeças das ovelhas enfermas para que as demais não sejam contaminadas; matamos os fetos e os recém-nascidos monstruosos; se nascerem defeituosos e monstruosos afogamo-los; não devido ao ódio, mas à razão, para distinguirmos as coisas inúteis das saudáveis'.
\end{abstract}

Já na época dos hebreus, a deficiência era sinal de impureza. Havia uma visão reducionista da questão da "imagem e semelhança a Deus". Predominava a visão de que o milagre que 
Da integração à inclusão social: o Estatuto das Pessoas com Deficiência e a concretização da inclusão pelos direitos assegurados

poderia acontecer às pessoas com deficiência era a cura, já que a deficiência era uma punição de Deus.

No período clássico havia uma busca pela sociedade ideal e perfeita. Platão e Aristóteles recomendavam a exclusão dos "imperfeitos". Platão ensinava que se deveria deixar morrer os que apresentassem corpo "mal organizado". Aristóteles, por sua vez, registrou, em Politica, a respeito de quais crianças deveriam ser abandonadas ou educadas, que deveria existir uma lei que proibisse a alimentação de crianças disformes (SILVA, 1997, p. 124).

Com o Cristianismo, a história mudou o seu curso quanto ao tratamento dessas pessoas, uma vez que todas as almas eram consideradas filhos de Deus. Surge, com isso, uma fase assistencial, da caridade e do amor, em que os homens passam a se preocupar com os seus semelhantes e se valem das pessoas com deficiência e necessitadas para praticar a caridade.

Neste período ocorre o modelo da segregação e as pessoas com deficiência passam a ser recolhidas em instituições. Como essas pessoas são retiradas da sociedade para viverem juntas em outro lugar, elas param de circular entre as demais e, com isso, tornam-se invisíveis. Em que pese essa segregação, deve-se reconhecer que nesta época a existência desse assistencialismo às pessoas com deficiência teve grande relevância, já que tais indivíduos estavam abandonados pelos seus parentes. Muitas crianças eram largadas na roda dos expostos por serem resultado de gravidez indesejada, por miserabilidade econômica da família ou por possuírem doenças degenerativas.

\section{A COMUNIDADE INTERNACIONAL NO TRATAMENTO DAS PESSOAS COM DEFICIÊNCIA E OS CONCEITOS DE INTEGRAÇÃO E INCLUSÃO SOCIAL}

No âmbito internacional, com a criação da Organização das Nações Unidas (ONU) após a Segunda Guerra Mundial, o mundo passa a se preocupar com questões relacionadas aos direitos humanos, já que surge um engajamento da sociedade pelo bem-estar comum.

A preocupação com as pessoas deficientes aumentou após as duas grandes guerras, porque a comunidade se deparou com milhares de soldados e civis vítimas de limitações em sua locomoção, audição e visão ocasionadas pelos combates. Essas pessoas tornadas deficientes com os conflitos passaram a exigir reabilitação e acessibilidade para a sua reintegração na sociedade.

Em 1955 foi aprovada a Recomendação número 99 da Organização Internacional do Trabalho (OIT), para tratar da "reabilitação das Pessoas Deficientes".

Posteriormente, a Assembleia Geral da ONU empreendeu esforços para aprovar declarações acerca dos direitos dessas pessoas com deficiência. Assim, aprovou em 1971, a Declaração dos Direitos das Pessoas com Retardo Mental e, em 1975, a Declaração dos Direitos das Pessoas com Deficiência. Apesar de serem diplomas normativos não vinculantes, por pertencerem a chamada "soft law", já representaram um grande avanço nos direitos das pessoas com deficiência.

Um ano depois, em 1976, houve a aprovação da Resolução 31/123, que proclamou o ano de 1981 como o "Ano Internacional para as pessoas deficientes", com o propósito de conscientizar o mundo acerca da necessidade de se implementar as declarações anteriores.

Nesta época, a Declaração então vigente, de 1975, adotava um modelo de integração social, anterior ao atual modelo de inclusão social. Com isso, importa mencionar os postulados $6 \mathrm{e}$ 9: 


\begin{abstract}
6. As pessoas deficientes têm direito a tratamento médico, psicológico e funcional, incluindo dispositivos protésicos e ortopédicos, a reabilitação médica e social, a educação, formação e reabilitação profissional, a apoio, aconselhamento, serviços de colocação e outros serviços que lhes permitam desenvolver ao máximo as suas capacidades e aptidões e acelerem os seus processos de integração ou reintegração social. ${ }^{1}$

9. As pessoas deficientes têm direito a viver com as suas famílias ou com pais adoptivos e a participar em todas as atividades sociais, criativas ou recreativas. Nenhuma pessoa deficiente será sujeita, no que diz respeito à sua residência, a um tratamento diferenciado não exigido pela sua situação ou pela melhoria que possa derivar de um tratamento diferenciado. Caso seja indispensável à permanência de uma pessoa deficiente num estabelecimento especializado, o ambiente e as condições de vida nele existentes serão tão aproximados quanto possível dos da vida normal de uma pessoa da sua idade. ${ }^{2}$
\end{abstract}

Nesse período adotou-se o modelo médico da abordagem da situação das pessoas com deficiência. Essa solução enxergava a deficiência como doença que necessitava de tratamento ou cura. Após o tratamento deste "defeito", a pessoa com deficiência poderia se tornar capaz de se integrar à sociedade. As pessoas com deficiência é que deveriam se adaptar aos modelos que já existiam na sociedade, e esta faria apenas pequenos ajustes.

Os progressos da medicina e a organização de serviços de reabilitação global tornavam esse processo de integração bem menos árduo, mas o trabalho de se chegar a uma situação integrada dependia apenas da própria pessoa deficiente. Para se integrar, o grupo de excluídos deveria provar que estava apto para viver junto com os outros em sociedade. Logo, os ajustes da sociedade para receber essas pessoas reabilitadas eram apenas superficiais.

A atenção da sociedade e do Estado era voltada ao reconhecimento dos problemas de integração da pessoa com deficiência, para que esta desenvolvesse estratégias para minimizar os efeitos da deficiência em sua vida cotidiana. A aplicação de tal formato acarretou na disseminação, entre as pessoas deficientes, da pobreza, da invisibilidade e da perenização de conceitos prestabelecidos negativos, como o entendimento de que deficientes são meros destinatários de misericórdia. Esse esquema falha na medida em que estimula a visão da deficiência como uma disformidade pessoal e afasta a compreensão de que são necessárias políticas de inclusão voltadas a esse público (RAMOS, 2017, p. 237).

No contexto do modelo médico, citando o caso das crianças surdas, elas devem aprender a falar o português a qualquer custo, talvez nunca aprendendo a língua de sinais brasileira (Libras). Por influência deste formato, nos dias de hoje, em diversos países em desenvolvimento, a linguagem de sinais ainda é desconhecida ou é confundida com mímicas e linguagens gestuais informais. No Brasil, somente em 2002 a Libras e os outros recursos de comunicação a ela associados foram reconhecidos como meio legal de comunicação, por meio da Lei $\mathrm{n}^{\mathrm{o}}$ 10.435/02 (WERNECK, 2004, p. 17).

Não dá para se negar que para a época houve um grande avanço, pois foram realizados esforços a fim de que as pessoas com deficiência participassem de reabilitações, objetivando a

\footnotetext{
1 6. Disabled persons have the right to medical, psychological and functional treatment, including prosthetic and orthetic appliances, to medical and social rehabilitation, education, vocational training and rehabilitation, aid, counselling, placement services and other services which will enable them to develop their capabilities and skills to the maximum and will hasten the processes of their social integration or reintegration.

2 9. Disabled persons have the right to live with their families or with foster parents and to participate in all social, creative or recreational activities. No disabled person shall be subjected, as far as his or her residence is concerned, to differential treatment other than that required by his or her condition or by the improvement which he or she may derive therefrom. If the stay of a disabled person in a specialized establishment is indispensable, the environment and living conditions therein shall be as close as possible to those of the normal life of a person of his or her age.
} 
Da integração à inclusão social: o Estatuto das Pessoas com Deficiência e a concretização da inclusão pelos direitos assegurados

diminuição de suas limitações, bem como se iniciava um processo de integração desses indivíduos à sociedade, evitando-se que eles vivessem segregados ou confinados no seu espaço, o que restringia as suas atividades e oportunidades sociais. Já se falava em promover condições adequadas para que eles tivessem acesso à sociedade sem obstáculos, às instalações e aos equipamentos sociais relativos à educação, trabalho, esportes e outras formas de recreação.

Por outro lado, não havia inclusão e, conforme já ressaltado, as pessoas com deficiência é que precisavam se adaptar à sociedade para se integrar, inexistindo esforço desta última para a plena acomodação das pessoas com deficiência. Faltava reconhecer que nem todas as pessoas conseguem se reabilitar, e que deveriam ocorrer mudanças substanciais na sociedade para permitir que as pessoas com deficiência tivessem acesso a todos os direitos e não apenas a alguns; a inserção não deveria ser parcial e condicionada à capacidade individual de integração, mas sim total e incondicionada, independentemente do grau de limitação.

De qualquer forma, o conceito da integração permitiu que se empreendessem esforços para que a sociedade rompesse preconceitos.

Apenas a partir de 1981, no Ano Internacional da Pessoa Deficiente, promulgado pela ONU, a pessoa com deficiência passou a se organizar politicamente. Antes disso, caminhou em silêncio, excluída ou segregada em entidades (FIGUEIRA, 2008, p. 115).

No dia 7 de junho de 1999 surge a Convenção Interamericana para a Eliminação de Todas as Formas de Discriminação contra as Pessoas Portadoras de Deficiência. O Brasil assinou o documento um dia depois, o Congresso Nacional o aprovou em 15 de agosto de 2001 e a promulgação ocorreu em 8 de outubro desse mesmo ano. Essa Convenção ainda usou em seu texto a expressão "integração social".

Posteriormente, após um processo que durou cinco anos, a comunidade internacional conseguiu aprovar uma Convenção sobre os Direitos das Pessoas com Deficiência no ano de 2006.

O movimento das pessoas com deficiência culmina com a ratificação, pelo Brasil, da Convenção sobre os Direitos das Pessoas com Deficiência. A participação direta e efetiva desse grupo de indivíduos não foi fruto do acaso, tendo decorrido de seu paulatino fortalecimento, até a exigência de direitos civis, políticos, sociais e econômicos (GARCIA, 2011).

A Convenção da Organização das Nações Unidas sobre os Direitos das Pessoas com Deficiência e seu Protocolo Facultativo foram assinados pelo Brasil na cidade de Nova York, em 30 de março de 2007. Trata-se do primeiro diploma internacional acerca desses direitos com caráter vinculante. No Brasil, essa Convenção teve elevada importância, já que foi o primeiro Tratado Internacional de Direitos Humanos aprovado com quórum de emenda constitucional, conforme o procedimento previsto no art. $5^{\circ}, \S 3^{\circ}$, da Constituição Federal de 1988. Entrou em vigor no Brasil em 25 de agosto de 2009, através do Decreto 6.949.

Essa Convenção também trouxe uma evolução na expressão utilizada para se referir a esse grupo de pessoas. Na Declaração de 1971, utilizou-se a expressão "retardo mental"; na Declaração de 1975, "pessoas deficientes", na Convenção Interamericana, aderiu-se à expressão "portador de deficiência", todas estas expressões sofreram críticas ao longo do tempo.

Finalmente, a partir de muitos debates, o termo "pessoa com deficiência" foi empregado no texto da Convenção sobre os Direitos das Pessoas com Deficiência, com a finalidade de valorizar o cidadão e mostrar dignidade em relação à realidade da deficiência. Conforme esse diploma internacional as pessoas com deficiência são: 
aquelas que têm impedimentos de longo prazo de natureza física, mental, intelectual ou sensorial, os quais, em interação com diversas barreiras, podem obstruir sua participação plena e efetiva na sociedade com as demais pessoas. (art. $1^{\circ}$, final).

Como se percebe, o conceito de deficiência considerou a limitação funcional adjetivada da forma como o mundo acordou e também considerou que essas limitações obstruem a participação plena na sociedade quando somadas com as diversas barreiras. Ou seja, se eliminadas as barreiras arquitetônicas, de comunicação e atitudinais, elimina-se a limitação biológica.

A Convenção sobre os Direitos das Pessoas com Deficiência positivou o modelo social da deficiência, da inclusão, contrapondo-se ao modelo médico visto anteriormente, que sustenta ideologicamente o paradigma da integração. A adoção do modelo social pode ser verificada no art. $3^{\circ}$ da Convenção, que traz como um de seus princípios, "a plena e efetiva participação e inclusão na sociedade".

Conforme André de Carvalho Ramos (2017, p. 237), esse formato, também chamado de "modelo de direitos humanos":

vê a pessoa com deficiência como ser humano, utilizando o dado médico apenas para definir suas necessidades. A principal característica é a abordagem de "gozo de direitos sem discriminação". Este princípio de antidiscriminação acarreta a reflexão sobre a necessidade de políticas públicas para que seja assegurada a igualdade material, consolidando a responsabilidade do Estado e da sociedade na eliminação das barreiras à efetiva fruição dos direitos do ser humano. Assim, não se trata mais de exigir da pessoa com deficiência que esta se adapte, mas sim de exigir, com base na dignidade humana, que a sociedade trate seus diferentes de modo a assegurar a igualdade material, eliminando as barreiras à sua plena inclusão.

A adoção do modelo social não pressupõe o abandono da reabilitação e dos tratamentos médicos. Significa que apesar de eles serem importantes, não devem constituir condição à efetividade dos direitos das pessoas com deficiência; mesmo porque nem sempre a reabilitação é atingível. A deficiência faz parte da diversidade humana e não inviabiliza uma vida plena por parte de quem a suporta. $\mathrm{O}$ que incapacita o indivíduo com deficiência para a plenitude de sua potencialidade é o meio em que está inserido, de modo que se o ambiente for adaptado para o acesso universal a bens e serviços, os deficientes são elevados a condições equiparadas àquela das demais pessoas. Logo, a sociedade precisa eliminar as barreiras existentes e construir as pontes necessárias.

Quando todos esses acessos estiverem garantidos é que haverá distribuição equitativa de oportunidades. Por expandir e dar complexidade ao sentido do vocábulo deficiência, o modelo social fortalece as reflexões sobre o valor das diferenças individuais e traz o assunto para o contexto de diversidade, direitos humanos e sustentabilidade do sistema (WERNECK, 2004, p. 18).

Dessa maneira, o modelo social da deficiência confere maior intensidade ao ativismo social em torno dessa condição existencial, dados os instrumentos analíticos e políticos que lhes são característicos, e desloca para o corpo social o enfrentamento da questão, para que não fique restrita à vida privada e dos cuidados familiares, situação observada nos modelos biomédicos (SANTOS, 2008, p. 506).

Por fim, como mais um poderoso instrumento de inclusão social especificamente para as pessoas com deficiência visual, foi celebrado em junho de 2013, no âmbito da Organização das Nações Unidas, o Tratado de Marraquexe, em Marrocos. Por meio deste documento, os países signatários se comprometem a criar instrumentos em suas legislações internas de reprodução e distribuição de obras, livros e textos em formato acessível às pessoas cegas, com deficiência visual, ou com outras dificuldades de leitura. Há compromisso em atualizar leis antiquadas que estejam impedindo que obras sejam convertidas e distribuídas em formato mais acessível. É um 
Da integração à inclusão social: o Estatuto das Pessoas com Deficiência e a concretização da inclusão pelos direitos assegurados

acordo internacional que possibilita o acesso à cultura. Trata-se de mais um Tratado de Direitos Humanos aprovado no Brasil com "status" de norma constitucional. O Brasil ratificou em 2015 e o Tratado passou a ter vigor internacional em 30 de setembro de 2016.

\section{A LEI DE INCLUSÃO BRASILEIRA E A CONCRETIZAÇÃO DE SEUS DIREITOS}

O Brasil já vinha regulamentando os direitos das pessoas com deficiência em sua Constituição Federal em diversos dispositivos e também em algumas leis esparsas.

Há leis próprias para a política de inclusão, acessibilidade e garantias para as pessoas surdas, cegas e com baixa visão. Importantes direitos estão inseridos, de forma transversal, na legislação geral da saúde, educação, trabalho, proteção social, cultura e esporte. Outras leis mais recentes regulamentam alguns aspectos da pessoa com deficiência como, por exemplo, a acessibilidade nos programas habitacionais públicos e a política de mobilidade urbana (MAIOR, 2016).

Em relação à norma abrangente, a primeira lei federal sobre as pessoas com deficiência é $\mathrm{a} \mathrm{n}^{\mathrm{0}} 7.853 / 1989$. A lei dispõe sobre o apoio às pessoas portadoras de deficiência, sua integração social, a Coordenadoria Nacional para Integração da Pessoa Portadora de Deficiência (CORDE), além de instituir a tutela jurisdicional de interesses coletivos ou difusos dessas pessoas e disciplinar a atuação do Ministério Público; também define crimes e outras providências.

Em que pese o grande avanço da lei supramencionada, a atual Lei de Inclusão (Lei $\mathrm{n}^{\circ}$ 13.146/2015) traduz uma verdadeira conquista social: coaduna-se com a Convenção sobre os Direitos das Pessoas com Deficiência e traz a plena inclusão de pessoas que antes eram vistas como absolutamente e relativamente incapazes.

Mas é preciso que haja real concretude desses direitos. Nesse sentido, com razão, Tércio Sampaio Ferraz Júnior (2007, p. 150):

existe um paradoxo na sociedade, que, de um lado, está obsessivamente preocupada em definir e proclamar uma lista crescente de direitos humanos de respeito e proteção ao deficiente; de outro, impotente para fazer descer do plano de um formalismo abstrato e inoperante esses direitos, de modo a levá-los a uma efetivação concreta nas práticas sociais.

Portanto, o objetivo não é apenas listar as grandes mudanças, mas sim descrever como elas podem ser efetivadas na prática.

Em primeiro lugar, o art. $6^{\circ}$ do Estatuto deixa claro que "a deficiência não afeta a plena capacidade civil da pessoa". Já o art. 84 estabelece: "a pessoa com deficiência tem assegurado o direito ao exercício de sua capacidade legal em igualdade de condições com as demais pessoas".

Com isso, os artigos $3^{\circ}$ e $4^{\circ}$ do Código Civil Brasileiro foram reestruturados eliminandose a incapacidade absoluta, por falta de necessário discernimento para as práticas dos atos da vida civil, e a incapacidade relativa dos excepcionais, aqueles sem desenvolvimento mental completo. A partir de agora, as pessoas com deficiência mental passam a ter plena capacidade para os atos da vida civil. Desde janeiro de 2016, o único critério para a incapacidade absoluta é o etário. Prestigiou-se a dignidade e a liberdade desse grupo de pessoas que vinha lutando pela conquista de seus direitos. A ótica agora é que as próprias pessoas com deficiência sabem o que é melhor para elas e devem decidir o seu destino: "nada sobre nós, sem nós". As pessoas com deficiência são sujeitos de direitos e possuem capacidade de fato. 
Com essa mudança, as pessoas com deficiência possuem incentivos legais para assumir outra postura que não a típica do papel de deficiente. O rótulo de deficiente, de pessoa com anormalidade, atingia o sujeito em sua totalidade, impedindo que ele pudesse crescer e se desenvolver de forma natural e satisfatória, o que acabava por afetar também a sua família, que ficava presa aos cuidados de uma pessoa considerada totalmente dependente.

Infelizmente, as pessoas com algumas limitações já eram programadas para ter atitudes e comportamentos dependentes e infantilizados, sem oportunidade de demonstrar habilidade para interagir com a sociedade mais ampla. Isso porque elas próprias se percebiam e eram percebidas apenas como deficientes, sendo consideradas incapazes e limitadas, tendo sempre os seus defeitos enfatizados.

Atualmente, enxerga-se a pessoa com deficiência como uma pessoa com imensas possibilidades, com capacidade de decidir e direcionar a sua vida cotidiana com autonomia e independência. O novo estatuto, conforme a Convenção sobre as pessoas com deficiência, prestigia a dignidade da pessoa humana.

O reconhecimento da capacidade plena da pessoa emancipada não significa que ela nunca precise do auxílio de outrem para o exercício de sua capacidade. Justamente para conciliar a autonomia da pessoa com deficiência e a necessidade fática de medidas protetivas, é que o Código Civil criou um instituto alternativo à curatela: a tomada de Decisão Apoiada (art. 1783-A).

Este instituto é inédito no nosso ordenamento e foi inserido pelo art. 116 da Lei de inclusão brasileira, que obedeceu a mandamento assumido pelo Brasil e pelos demais Estados-partes da Convenção sobre as Pessoas com Deficiência (aprovada como emenda constitucional). Conforme o art. 12, item 3 da Convenção: "Os Estados-partes tomarão medidas apropriadas para prover o acesso de pessoas com deficiência ao apoio que necessitarem no exercício de sua capacidade legal"'.

Esse sistema da tomada de decisão apoiada se coaduna com os princípios previstos no art. $3^{\circ}$ da Convenção: "respeito à dignidade, à autonomia individual e à liberdade de fazer as próprias escolhas". De fato, a própria pessoa com deficiência escolherá "pelo menos duas pessoas idôneas, com as quais mantenha vínculos e que gozem de sua confiança, para prestar-lhe apoio na tomada de decisão sobre atos da vida civil, fornecendo-lhes os elementos e as informações necessários para que possa exercer a sua capacidade" (art. 1783-A, caput, do Código Civil). Esse instituto será muito útil para pessoas que descubram, por exemplo, que estão com Alzheimer, principalmente em idade precoce. Mas note-se que o instituto não se aplica apenas às pessoas com deficiência mental, já que o dispositivo se refere ao gênero "pessoa com deficiência". Com isso, pode também ser bastante útil para facilitar a vida de pessoas com deficiência sensorial.

Novamente com fundamento na liberdade, a pessoa emancipada formulará um termo, junto com os seus apoiadores, estabelecendo os limites do apoio a ser oferecido e os compromissos dos apoiadores, inclusive o prazo de vigência do acordo e o respeito à vontade, aos direitos e aos interesses da pessoa que devem apoiar ( $\S 1^{\circ}$ do art. 1783-A). Esse regime se constituirá pela via judicial. Antes de se pronunciar sobre o pedido de tomada de decisão apoiada, o juiz, assistido por equipe multidisciplinar, após oitiva do Ministério Público, ouvirá pessoalmente o requerente e as pessoas que lhe prestarão apoio $\left(\S 3^{\circ}\right)$. A pessoa com deficiência terá apoiadores não porque lhe foram impostos, mas sim porque assim preferiu.

A curatela ainda subsiste, mas será adotada de forma excepcional, proporcional às necessidades e às circunstâncias de cada caso, e durará o menor tempo possível (conforme art. 84, § $3^{\circ}$, da Lei 13.146/15). Isso porque ainda é possível a incapacidade civil relativa daqueles que, por causa transitória ou permanente, não puderem exprimir a sua vontade $\left(\operatorname{art} .3^{\circ}, \mathrm{III} \mathrm{c} / \mathrm{c}\right.$ art. 
Da integração à inclusão social: o Estatuto das Pessoas com Deficiência e a concretização da inclusão pelos direitos assegurados

1767, I, ambos do Código Civil). O detalhe é que agora a curatela está muito mais restrita, já que afetará apenas os atos relacionados aos direitos de natureza patrimonial e negocial, não afetando os direitos personalíssimos, inerentes a qualquer pessoa humana, tais como o próprio corpo, a sexualidade, o matrimônio, a privacidade, a educação, a saúde, o trabalho e o voto (art. 85, da Lei de inclusão).

É de importância salutar o art. 1.777 do Código Civil (incluído pelo novo Código de Processo Civil): "as pessoas referidas no inciso I do art. $1.767^{3}$ receberão todo o apoio necessário para ter preservado o direito à convivência familiar e comunitária, sendo evitado o seu recolhimento em estabelecimento que os afaste desse convívio". Este dispositivo busca preservar a inclusão social, evitando-se que regridamos ao modelo da segregação.

Também buscando garantir a capacidade civil plena da pessoa com deficiência, o novo Código de Processo Civil previu que "o curador deverá buscar tratamento e apoios apropriados à conquista da autonomia pelo interdito" (art. 758). Isto é, a curatela deve subsistir apenas pelo tempo necessário.

O ideal é que a tomada de decisão apoiada torne a curatela um instituto em desuso. Porém, apenas o tempo demonstrará se isso ocorrerá, uma vez que não se desconhece que há casos em que a pessoa não consegue gerir a sua própria vida. Para essas situações, recomenda-se a proteção jurídica, já que o sujeito é ainda mais vulnerável. Mas o intuito da reforma é que a curatela seja a "ultima ratio", e não a primeira opção, conforme vinha acontecendo. Em suma, os institutos atuais são menos invasivos na esfera existencial, já que se evita uma interdição e curatela geral.

Nesse momento, após o reconhecimento da pessoa com deficiência como sujeito de direito, capaz de conduzir a sua própria história, urge comentar acerca da efetivação dos direitos previstos no Estatuto. A sociedade tem a responsabilidade de se transformar, tornando-se mais inclusiva e menos excludente, concretizando o quanto antes os direitos desse segmento vulnerável de pessoas. As conquistas não podem parar, pois apesar do avanço em abstrato, a sociedade agora precisa se adequar para garantir os direitos concretamente.

A Lei Brasileira de Inclusão tratou da educação no capítulo quarto. A educação constitui direito da pessoa com deficiência, assegurado sistema educacional inclusivo em todos os níveis e aprendizado ao longo de toda a vida, de forma a alcançar o máximo desenvolvimento possível de seus talentos e habilidades físicas, sensoriais, intelectuais e sociais, segundo suas características, interesses e necessidades de aprendizagem (art. 27).

Durante muitos anos adotamos o modelo de educação especial, em que a pessoa com limitações, com o objetivo de se reabilitar e ser reintegrada em sociedade estudava em instituições que mantinham equipes multidisciplinares.

A noção da necessidade de segregação de alunos com deficiência como forma neces-
sária para a sua educação deve ter sido muito mais contundente em nosso país, já que
não há informação de qualquer outra iniciativa não segregacionista, até, pelo menos,
o início da década de 1930 , quando foram criadas as primeiras classes especiais em
escolas regulares. (BUENO, 2006, p. 174, apud FIGUEIRA, 2008, p. 111).

A segregação não é prejudicial apenas para a criança com deficiência, mas também para os outros alunos, já que quanto mais a criança interagir espontaneamente em situações diferenciadas tanto mais ela adquirirá o genuíno conhecimento. A segregação prejudica a todos, porque impede que as crianças das escolas regulares tenham oportunidade de conhecer todas as dimensões e desafios da vida humana. Evoluir não significa tratar igual, pois as pessoas são diferentes.

${ }^{3}$ I - aqueles que, por causa transitória ou permanente, não puderem exprimir sua vontade. 
Alunos diferentes terão oportunidades diferentes, para que o ensino alcance os mesmos objetivos. Incluir é abandonar estereótipos (WERNECK, 2000, p. 56).

O Estatuto prevê o modelo de inclusão, que é mais avançado que a integração. Na política da integração, garante-se que a pessoa com deficiência tenha acesso aos mesmos bens que as pessoas sem deficiência; no aspecto da educação garante-se que ela possa frequentar as mesmas escolas. Mas essa criança só tem a garantia de estar presente, e ela é quem deve se esforçar para acompanhar a turma, contratando, por exemplo, professores particulares para suprir suas dificuldades. Já na educação inclusiva, a classe e os professores precisam se adaptar para que o vulnerável possa aprender. Logo, é necessário que as escolas contratem profissionais especializados, para ajudar e perceber as dificuldades dessas pessoas com limitações. Além disso, as escolas devem fornecer cursos e palestras aos professores para que eles aprendam novas didáticas, com a finalidade de que aprendam técnicas de inclusão das pessoas com dificuldades. É preciso que os professores tenham sensibilidade para adaptar a sua pedagogia, ao invés de insistirem nos métodos até então utilizados. Enfim, a escola é que tem a obrigação de romper as barreiras, criando respostas educativas para as necessidades e limitações específicas de cada aluno.

A escola é um dos principais ambientes para a inclusão, pois as crianças e adolescentes, pessoas em desenvolvimento, são inocentes e já crescem aprendendo a lidar com a diversidade, para que se formem pessoas melhores, despidas de qualquer preconceito na fase adulta. Na sociedade inclusiva todos aprendem: as pessoas com limitações passam a ter a oportunidade de demonstrar habilidade para interagir com a sociedade mais ampla, e os outros alunos crescem conhecendo a diversidade humana. As crianças e os adolescentes são, inclusive, capazes de modificar os conceitos ou preconceitos de seu lar, tornando os adultos com quem convivem pessoas melhores, respeitadoras dos direitos humanos. A sociedade inclusiva começa com uma educação inclusiva, uma educação cidadã.

Mas é claro que a sociedade e as instituições, como o Ministério Público e a Defensoria Pública, precisam fiscalizar o cumprimento da educação inclusiva nas escolas. Não são raras as vezes que nos deparamos com reportagens sobre escolas que alegam não ter mais vaga quando a mãe diz que seu filho tem alguma deficiência, e, no mesmo dia alegam ter disponibilidade para crianças sem limitações. Assim, só resta proliferar um movimento de exigência dos direitos listados na lei. Essa tarefa não deve ficar sob a responsabilidade exclusiva do grupo de pessoas violado em seus direitos.

Por fim, é importante que a escola ensine direitos humanos e realize atividades de conscientização, a fim de eliminar preconceitos e estigmas entre os alunos. Participando de atividades de sensibilização, esses alunos serão capazes de mudar o futuro da sociedade.

A locomoção é uma das principais dificuldades encontradas pelas pessoas com deficiência e um dos mais importantes direitos, uma vez que de nada adianta garantir educação, trabalho, cultura, saúde e lazer, se a pessoa não consegue chegar aos locais. No que tange ao direito ao transporte e à mobilidade da pessoa com deficiência ou com mobilidade reduzida, o artigo 46 estabelece que esse direito será assegurado em igualdade de oportunidade com as demais pessoas, por meio de identificação e de eliminação de todos os obstáculos e barreiras ao seu acesso. Nos dispositivos seguintes há previsão de direitos de mobilidade nos transportes públicos, de incentivos à fabricação de carros adaptados e de vagas especiais para os carros desse grupo de pessoas emancipadas.

Após lutas para a concretização desses direitos, as vagas especiais em estacionamentos privados e nas vias públicas começam a ser definidas e devem, de fato, ser respeitadas. Os carros que não respeitam as vagas reservadas precisam ser guinchados; todos os Municípios devem prezar por essa fiscalização. 
Da integração à inclusão social: o Estatuto das Pessoas com Deficiência e a concretização da inclusão pelos direitos assegurados

Quanto à acessibilidade dos coletivos municipais, infelizmente em 2016 as cidades ainda não cumpriram integralmente o Decreto Presidencial no 5.296/2004 que determina que "a frota de veículos de transporte coletivo rodoviário e a infraestrutura dos serviços deste transporte deverão estar totalmente acessíveis no prazo máximo de cento e vinte meses a contar da publicação deste decreto". O prazo venceu em 2014. Mesmo após tanto tempo da publicação do Decreto, os veículos não estão 100\% adaptados. Levantamento inédito realizado em 2016 pelo "Fiquem sabendo"4 com base em dados da SPTrans (empresa municipal de transporte) obtidos por meio da Lei Federal $n^{\circ}$ 12.527/2011 (Lei de Acesso à Informação), aponta que 14\% dos 14.702 coletivos em circulação na cidade de São Paulo não têm itens básicos de acessibilidade para pessoas com deficiência ou com mobilidade reduzida. Se a grande cidade de São Paulo ainda não cumpriu totalmente a lei, imagine as outras cidades. Fora isso, há reclamações de cadeirantes de que os elevadores são velhos e às vezes não funcionam, e que os funcionários precisam ser treinados para lidar com o equipamento.

Em relação à acessibilidade, esta deve caminhar na direção do desenho universal, que, segundo o Estatuto das Pessoas com Deficiência (Lei 13.146/2015), é a "concepção de produtos, ambientes, programas e serviços a serem usados por todas as pessoas, sem necessidade de adaptação ou de projeto específico, incluindo os recursos de tecnologia assistiva" (art. $3^{\circ}$, inciso II).

\begin{abstract}
O desenho universal poderia ser chamado 'desenho inclusivo', ou seja, projeto que inclui todas as pessoas. Os produtos e ambientes feitos sob o desenho universal ou inclusivo não aparentam ser especialmente destinados a pessoas com deficiência, já que são feitos para a utilização por qualquer pessoa, deficiente ou não. Inclusive é possível que pessoas sem deficiência nem percebam, nesses produtos ou ambientes, certas especificidades que atendem às necessidades de pessoas com deficiência. (SASSAKI, 2006, p. 141).
\end{abstract}

A Lei Brasileira de inclusão trata da acessibilidade a partir do artigo 53, segundo o qual "a acessibilidade é direito que garante à pessoa com deficiência ou com mobilidade reduzida viver de forma independente e exercer seus direitos de cidadania e de participação social". Já o artigo $3^{\circ}$, inciso I, traz o conceito de acessibilidade como "possibilidade e condição de alcance para utilização, com segurança e autonomia, de espaços, mobiliários, equipamentos urbanos, edificações, transportes, informação e comunicação, inclusive seus sistemas e tecnologias, bem como de outros serviços e instalações abertos ao público, de uso público ou privados de uso coletivo, tanto na zona urbana como na rural, por pessoa com deficiência ou com mobilidade reduzida".

O Estatuto traz importantes obrigações de acessibilidade. Conforme o artigo 56, a construção, a reforma, a ampliação ou a mudança de uso de edificações abertas ao público, de uso público ou privadas de uso coletivo deverão ser executadas de modo a serem acessíveis. Os novos edifícios também deverão atender as regras de acessibilidade. Espera-se que haja fiscalização do cumprimento dessas regras.

Lamentavelmente, quando observamos as vias públicas, verificamos que a acessibilidade para cadeirantes está longe de ser alcançada, já que raramente encontramos rampas de acesso nas calçadas. Muitas mães também já devem ter percebido a dificuldade para subir e descer calçadas com um carrinho de bebê. Ao que parece existem algumas rampas bem distantes (quando existem) para fingir o cumprimento das leis. Enquanto a mobilidade nos transportes públicos tem recebido progressiva atenção, a acessibilidade entre o local que a pessoa com deficiência desce e até aonde ela tem que ir ainda possui muitas barreiras, já que as vias públicas estão longe de

${ }^{4}$ Cf. Fiquem sabendo. São Paulo não cumpre lei que prevê $100 \%$ dos ônibus adaptados para deficientes. Disponível em $<\mathrm{http}$ ://www.fiquemsabendo.com.br/2016/06/2-110-onibus-municipais-nao-sao-adaptados-para-deficientes-em-sp/> Acessado em: 24 de novembro de 2016. 
ser acessíveis, inclusive nas grandes cidades. Trata-se de medida simples de ser executada, mas que exige boa vontade dos administradores públicos.

As edificações são outro aspecto também relevante, já que o trajeto da pessoa é traçado para chegar a um local final. Dentro dos estabelecimentos também há a necessidade de rampas de acesso, mas poucos se preocuparam em fazer esta adaptação, pois ainda observamos prédios que possuem apenas escadas. Outra importante forma de efetivar a acessibilidade é admitindo a entrada e a permanência de cão-guia junto à pessoa com deficiência.

A população deve fazer essas exigências através de audiências públicas, abaixo assinados e até provocação da mídia para atrair a atenção de mais pessoas. É importante pleitear, nos Municípios, a elaboração de Plano Diretor de Acessibilidade com normas gerais e critérios básicos que promovam a acessibilidade das pessoas com deficiência ou com mobilidade reduzida.

A acessibilidade também inclui a efetivação da informação e da comunicação das pessoas com deficiência, não se reduzindo aos casos daqueles indivíduos que possuem limitações físicas. Importa também mudar a realidade social para a recepção das pessoas com limitações sensoriais. Deve haver estímulo e aumento do aprendizado da linguagem dos sinais para surdos, a fim de que audiências públicas, palestras, atrações culturais e profissionais sejam realizadas também com a presença de uma pessoa que se comunique por meio dessa linguagem. O "braille" para cegos também precisa ser difundido; espera-se que o compromisso do Brasil com o Tratado de Marraquexe realmente amplie a impressão de livros na linguagem "braille", para superar a fome do livro ${ }^{5}$, já que as estimativas apontam que nos países subdesenvolvidos apenas $1 \%$ dos livros publicados são adaptados para um formato acessível. É essencial que se assegure o acesso das pessoas cegas à cultura e ao aprendizado por meio da leitura. Todo livro que nasce digital, precisa nascer acessível.

Ainda no que tange à mobilidade, o Estatuto traz o conceito de tecnologia assistiva ou ajuda técnica, que consiste em:

produtos, equipamentos, dispositivos, recursos, metodologias, estratégias, práticas e serviços que objetivem promover a funcionalidade, relacionada à atividade e à participação da pessoa com deficiência ou com mobilidade reduzida, visando à sua autonomia, independência, qualidade de vida e inclusão social. (art. $3^{\circ}$, inciso III).

A tecnologia assistiva é um termo usado para identificar todos os produtos, recursos e serviços que contribuem para proporcionar ou ampliar as habilidades funcionais de pessoas com deficiência com a finalidade de promover a sua inclusão social.

Como existem pessoas impedidas de se locomover, que possuem membros amputados, com problemas de audição, de visão etc. elas poderão ter uma melhor qualidade de vida com a utilização de tecnologias assistivas.

Nas palavras de Mara Gabrilli (2008, p. 76):

com essas tecnologias, as deficiências das pessoas desaparecem. Essas tecnologias podem ser próteses ou órteses (equipamentos que substituem parte do corpo humano podendo ser implantadas ou não), aparelhos auditivos, sistemas de comunicação alternativos (principalmente usados por pessoas com paralisia cerebral), telefones para

\footnotetext{
5 Acessibilidade eletrônica para cidadãos com necessidades especiais. A Fome de Livros, um termo cunhado por George Kersher do consórcio DAISY expressa-se no facto de que no mundo desenvolvido, todos os anos, do total de livros publicados apenas 7\% são adaptados para um formato acessível para pessoas com incapacidade para ler ou manusear material impresso. Na Europa, nos Estados Unidos, no mundo desenvolvido, as pessoas com incapacidade para ler ou manusear material impresso têm a sorte de ter acesso a 7\% dos livros publicados nos seus países de origem. Até à pouco tempo atrás este número era apenas de $5 \%$. No mundo em vias de desenvolvimento, esta percentagem é bastante mais próxima do $1 \%$.
} 
Da integração à inclusão social: o Estatuto das Pessoas com Deficiência e a concretização da inclusão pelos direitos assegurados

surdos, softwares de voz para pessoas com deficiência visual e equipamentos tecnológicos em geral (pedalar uma bicicleta adaptada e andar por eletroestimulação, por exemplo). Esses são alguns casos de tecnologia que faz com que as pessoas com deficiências se integrem com mais facilidade.

Muito interessante é a criação em São Paulo de um Centro de Tecnologia Adaptada. Ainda segundo Gabrilli, a Prefeitura de São Paulo, por meio da Secretaria Especial da Pessoa com Deficiência e Mobilidade reduzida, criada em 2005 e comandada por ela até 2007, desenvolveu diversos projetos para promover a integração social das pessoas com deficiência, disponibilizando equipamentos com tecnologias que garantam sua autonomia. A ideia é que esse Centro seja expandido para todo o País.

O acesso a diversos recursos tecnológicos contribui para a remoção das barreiras existentes para as pessoas com limitações. É indispensável, também, estimular a pesquisa na inovação de tecnologias e sua consequente implementação, com o objetivo de possibilitar que as pessoas com deficiência conquistem a sua independência e possam participar dos meios mais usuais utilizados pelas outras pessoas da sociedade, a fim de que haja a equiparação de oportunidades e uma vida com dignidade.

No capítulo sexto do Estatuto, encontra-se o sagrado direito ao trabalho, sendo este garantido tanto nas pessoas jurídicas de direito público quanto de direito privado. $\mathrm{O}$ trabalho dignifica o homem, e isso inclui a pessoa com deficiência.

As cotas reservadas às pessoas com deficiência, previstas no art. 37, VIII, da Constituição Federal já é um grande instrumento de inclusão social e de efetivação da igualdade material. Antes, porém, cumpre mencionar que a vaga reservada não pode ser enxergada como um "prêmio", uma vez que a pessoa com deficiência só a obterá depois de demonstrado o preenchimento de requisitos mínimos. É sim uma forma de distribuir oportunidades e de reconhecer que as pessoas com deficiência são capazes de exercer funções ao lado das pessoas sem deficiência.

Quando se fala em “cargos ou empregos públicos”, isso inclui o Poder Judiciário e os cargos de juízes. Também engloba o ingresso em outras instituições, como nos cargos de promotores de justiça, defensores públicos, procuradores e policiais. Mas lamentavelmente ainda ocorre muito preconceito em algumas dessas instituições. Muitos candidatos concorrem na vaga reservada e outros não, por se considerarem capazes de disputar na concorrência geral.

Todavia, muitos acabam eliminados nas fases de aptidão física, de psicotécnico ou na fase oral. Quando surge uma dúvida se a pessoa possui alguma deficiência ela já é eliminada sem ter a chance de provar que não a possui. E caso detenha alguma limitação de forma incontroversa, menos chances ela apresenta. É surpreendente como os diagnósticos são feitos na maioria das vezes em um único dia para doenças que levam meses para serem confirmadas por um profissional especializado. Desprezam-se considerações de ordem pessoal, tais como nervoso, ansiedade ou surpresa. Nos casos de limitações físicas, muitos são eliminados por não serem capazes de realizar todas as provas de aptidão física. Isso demonstra como o preconceito é grave e como não se deposita a mínima confiança de que essas pessoas podem ser plenamente capazes para o exercício do cargo e, em muitos casos, até de forma mais eficiente que algumas pessoas sem deficiência.

Em caso de dúvida, a inclusão deve ser prestigiada. Para aferir o desempenho ou a capacitação do candidato, deve-se permitir seu ingresso no serviço público e acompanhá-lo no estágio probatório. Se tiver desempenho satisfatório, é caso de permanência no cargo; do contrário, deverá ser dispensado, por falta de habilitação necessária. A função do estágio probatório é exatamente verificar como se desempenha o funcionário no período. Portanto, só pode ser aferida a 
situação a partir da prática. Barrar o candidato em caso de incerteza é decidir contrariamente ao princípio da inclusão (ARAÚJO e RAGAZZI, 2007, p. 45).

Assim, qualquer cargo ou emprego público deve ser inclusivo, e não apenas os subalternos, em razão do princípio da igualdade, da não discriminação e da dignidade da pessoa humana.

O direito ao trabalho também deve ser assegurado na iniciativa privada. Os valores sociais do trabalho e da livre iniciativa são princípios fundamentais que não podem ser afastados da ideia de inclusão social. As empresas precisam proporcionar acessibilidade aos seus empregados que tenham adquirido uma deficiência de curto ou longo prazo, como também devem admitir em seu quadro de pessoal o ingresso de pessoas com deficiência. Uma empresa inclusiva é aquela que acredita na diversidade humana.

A política de inclusão da pessoa com deficiência no trabalho iniciou-se com o sistema de cotas compulsório. Em um primeiro momento, isso se mostrou necessário e apresentou resultados positivos. Todavia, atualmente é imprescindível a adoção de políticas mais abrangentes. Conforme o artigo 93 da Lei Previdenciária (Lei 8213/91), a empresa com cem ou mais empregados está obrigada a preencher de $2 \%$ até $5 \%$ dos seus cargos com beneficiários reabilitados ou pessoas portadoras de deficiência habilitadas.

O Ministério Público do Trabalho desempenha papel eficaz no cumprimento da política de cotas através da realização de termos de ajustamento de conduta com empresas que não estão cumprindo a lei. Havendo descumprimento do compromisso, tem-se a execução da multa prevista.

Fora a política compulsória de cotas, o Poder Público necessita observar o art. 27, item 1, alínea $h$ da Convenção sobre as Pessoas com Deficiência, que estabelece que os Estados-partes devem "promover o emprego de pessoas com deficiência no setor privado, mediante políticas e medidas apropriadas, que poderão incluir programas de ação afirmativa, incentivos e outras medidas". Logo, a concessão de incentivos fiscais, bem como de selos de responsabilidade social constituem excelentes formas de mudar a consciência dos administradores das empresas privadas para que elas sejam mais inclusivas. A imagem empresarial positiva pode estimular contratações acima da porcentagem de cotas obrigatórias por lei.

É preciso educação social no sentido de que a empresa tenha interesse em realizar um trabalho de responsabilidade social que seja transformador e viabilize a inclusão das pessoas com deficiência. A política de contratação não deve ser simbólica a fim de preencher as vagas com algumas pessoas com deficiência, mas sim deve ser centrada na competência profissional da pessoa com deficiência e na sua capacidade de ocupar o seu espaço no mercado de trabalho.

Com previsão no capítulo III, a pessoa com deficiência tem direito ao adequado tratamento da saúde. É assegurada atenção integral à saúde dessas pessoas em todos os níveis de complexidade, por intermédio do SUS, garantido acesso universal e igualitário (art. 18). Nos dispositivos subsequentes, percebe-se que a pessoa com deficiência tem direito a participar das políticas públicas de saúde a ela destinadas, que possui direito a habilitação e reabilitação, garantida a capacitação inicial e continuada, assim como acesso a medicamentos, e se a deficiência for física, tem direito a próteses e órteses. Analisando todos os dispositivos mencionados, constata-se que a pessoa com deficiência tem direito a todos os recursos disponíveis e também àqueles relacionados às especificidades de sua deficiência, em conformidade com o princípio da integralidade.

Ainda que tenhamos adotado um modelo social de inclusão, a pessoa com deficiência tem direito a tratamentos que auxiliem na diminuição da sua limitação. O modelo social convive com este raciocínio; a diferença em relação ao modelo médico é que o modelo social vai além, prega 
Da integração à inclusão social: o Estatuto das Pessoas com Deficiência e a concretização da inclusão pelos direitos assegurados

que as pessoas com deficiência possam conviver integralmente em sociedade com a eliminação de todas as barreiras, pois conforme já foi dito, nem sempre a reabilitação é possível. A sociedade também se adequa a ela, e não apenas ela é que terá que se reabilitar ao padrão imposto anteriormente pela sociedade. Mas esse paradigma não afasta o direito de a pessoa tentar eliminar suas limitações. Constitui dever do Estado oferecer atendimento multidisciplinar na área de prevenção e reabilitação de deficiências, por meio de uma rede de médicos, fisioterapeutas, fonoaudiólogos e assistentes sociais. Esses profissionais devem definir a melhor forma de atendimento.

Assim, todos os tratamentos e medicamentos devem ser inseridos nas políticas do Sistema Único de Saúde em razão da integralidade e devem ser universais a todos que necessitem. O SUS já oferece gratuitamente equipamentos sensoriais e de locomoção às pessoas com deficiência. Mas o tratamento e as tecnologias adequados devem estar sempre atualizados nas Portarias e efetivamente disponibilizados. Em caso de inércia, resta a judicialização. O SUS desempenha essas funções com o objetivo de promover a inclusão social e melhorar a qualidade de vida dessas pessoas.

\section{CONCLUSÃO}

A inclusão de pessoas com deficiência vem sendo introduzida no Brasil há pouco tempo. Nossa história é marcada pela exclusão, num período que se considerava a pessoa com deficiência como inválida e inútil para a sociedade, e segregação, com o desenvolvimento de políticas públicas de assistencialismo, piedade e discriminação, tudo construído culturalmente.

A posterior fase da integração social foi uma grande conquista para a época, já que se iniciou um processo de contato e interação entre as pessoas com deficiência e a totalidade da sociedade, opondo-se à exclusão e à segregação. Mas nessa etapa, por prevalecer o modelo médico de deficiência, as pessoas com limitações deveriam passar por tratamentos médico, psicológico, funcional e, também, por processos de reabilitação de acordo com as suas limitações: física, social, educacional etc. Esses serviços serviam para que os indivíduos com deficiência desenvolvessem e aprimorassem as suas capacidades e habilidades, de modo a que pudessem, após a reabilitação, ser integrados à sociedade. Em outras palavras, a sociedade, estática, unicamente aguardava o esforço de adaptação da pessoa, dinâmica.

Já a atual teoria da inclusão social se propõe a realizar uma mudança cultural. Não se nega a utilização de reabilitação e mecanismos que auxiliem o sujeito na superação das limitações, mas se vai além, pois a inclusão social significa tornar essas pessoas participantes da vida social, econômica e política, aceitando as suas limitações sem forçá-las a se adequarem à sociedade. A inclusão social é o conjunto de meios e ações que visam combater a exclusão das pessoas com deficiência dos benefícios da vida em sociedade. Significa oferecer as mesmas oportunidades de acesso a bens e serviços para essas pessoas que sofreram discriminação ao longo dos anos. Para isso, é preciso romper com o descaso do Poder Público e de diversos setores da sociedade. A sociedade deve ter a responsabilidade de eliminar todos os problemas estruturais que venham a impedir a concretização dos direitos fundamentais das pessoas com deficiência, visto que tais indivíduos são sujeitos de direitos e merecem igualdade de condições em relação aos demais membros da sociedade em todos os aspectos da vida, com a mesma possibilidade de exercício da sua cidadania.

É importante conhecermos todos os conceitos inclusivos que abrangem valores que devem ser inculcados, difundidos, introduzindo novas práticas culturais para que possamos viver em uma sociedade realmente igualitária. Em relação ao direito à educação inclusiva, a classe e os professores devem receber a pessoa com deficiência, adaptando a metodologia para que ela 
possa aprender. É necessário que as escolas contratem profissionais especializados, para que se ofereçam condições, às pessoas com deficiência, possibilitando que as dificuldades existenciais venham a ser superadas. Com isso todos ganham, na medida em que a educação é a força motriz do processo de mudança cultural e, nesse caso, alunos sem deficiência também seriam beneficiados, pois aprenderiam, com maior propriedade, a lidar com a diversidade humana.

Os direitos de locomoção e acessibilidade são aqueles que devem ser imediatamente concretizados porque os exercícios dos demais deles dependem. Se não existir um desenho universal, com uma logística que garanta a chegada das pessoas com deficiência a todos os lugares, não há efetivamente direito à educação, ao trabalho, ao lazer, à liberdade de culto, às atividades esportivas etc. Assim, todos os obstáculos existentes no trajeto da pessoa com deficiência que impeçam o seu deslocamento em razão de sua condição existencial devem ser eliminados. Deve haver todo tipo de transporte público adaptado, calçadas acessíveis e edifícios também acessíveis. É preciso mudança nas políticas públicas, fiscalização no cumprimento de leis que imponham a obrigação de fazer e ações extrajudiciais ou até judiciais para a conquista da plena acessibilidade e mobilidade sociais.

No aspecto do direito ao trabalho, tanto o serviço público quanto a iniciativa privada devem conceder igualdade de oportunidades. Já existe a política de cotas no ambiente laboral como um todo, mas as regras estabelecidas precisam ser fiscalizadas e exigidas, pois não são raras às vezes em que editais relativos a concursos são impugnados pela falta de previsão da reserva de vagas e que empresas privadas deixam de obedecer à lei de cotas.

Seria adequado, no âmbito do serviço público, que as bancas examinadoras fossem inclusivas, dando chance de participação às pessoas com deficiência. Deve-se registrar que a existência de deficiência, na maioria das vezes, não interfere na aptidão individual para o cargo, e que o estágio probatório parece o instituto temporário pertinente para aferir a compatibilidade entre a condição existencial e as exigências laborais.

Quanto ao âmbito privado, entende-se que a política do Estado deve ir além da repressão, que prevê, por exemplo, a aplicação de multas a empregadores que não cumprem as cotas, devendo, sobretudo, gerar estímulos àqueles que voluntariamente assumam a devida responsabilidade social. Essa atuação positiva pode se dar por intermédio de incentivos fiscais e selos que premiem a empresa com uma imagem de empresa cidadã. Prêmios podem ter mais efetividade do que a coerção.

Consideramos que nesses novos tempos a política de inclusão precisa ser ampliada e, desse modo, faz-se coerente o incentivo ao desenvolvimento da tecnologia assistiva, que estimula e intensifica a inclusão. Frise-se que o acesso aos recursos tecnológicos, de forma indubitável, contribui para a remoção das barreiras existentes, já que possibilitam que as pessoas com deficiência conquistem a sua autonomia e independência, tendo maior controle nos vários ambientes físicos e sociais que pretendam frequentar para atingir seus objetivos de vida.

Por fim, a saúde das pessoas com deficiência deve ser garantida pelo SUS já que este é um programa universal. As pessoas com deficiência têm direito aos tratamentos e remédios, como toda pessoa, e também a tratamentos e recursos tecnológicos específicos para a sua limitação. Para tanto, a atualização das Portarias precisa ser perene, visando o adequado atendimento às condições existenciais próprias destes sujeitos, garantindo-lhes uma vida digna e igualitária.

Todos nós somos responsáveis por um trabalho que efetive a inclusão social das pessoas com deficiência, ajudando-as a resgatar a sua autoconfiança e a vontade de vencer, permitindo e estimulando que elas participem de todas as políticas públicas a elas dirigidas, e que possam 
Da integração à inclusão social: o Estatuto das Pessoas com Deficiência e a concretização da inclusão pelos direitos assegurados

exercer todos os seus direitos fundamentais sem barreiras intransponíveis e em igualdade de condições em relação a todos os outros membros da sociedade.

\section{REFERÊNCIAS}

ACESSIBILIDADE ELETRÔNICA PARA CIDADÃOS COM NECESSIDADES ESPECIAIS. Disponível em: <http://www.acessibilidade.gov.pt/arquivo/361> Acesso em: 24 nov. 2016.

ARAUJO, Luiz Alberto David; RAGAZZI, José Luiz. A Proteção Constitucional das Pessoas Portadoras de Deficiência. Revista do Advogado, ano XXVII, n. 95, dez. 2007.

FERRAZ JÚNIOR, Tércio Sampaio. O Deficiente na perspectiva da Antropologia Filosófica. Revista do Advogado, ano XXVII, n. 95, dez.2007.

FIGUEIRA, Emílio. Caminhando em silêncio: Uma introdução à trajetória as pessoas com deficiência na história do Brasil. 2. ed., São Paulo: Giz Editorial, 2008.

FIQUEM SABENDO. São Paulo não cumpre lei que prevê $100 \%$ dos ônibus adaptados para deficientes. Disponível em <http://www.fiquemsabendo.com.br/2016/06/2-110-onibus-municipais-nao-sao-adaptados-para-deficientes-em-sp/> Acesso em: 24 nov. 2016.

GABRILli, Mara. Mobilidade Pessoal. A Convenção sobre os Direitos das Pessoas com Deficiência Comentada / Coordenação de Ana Paula Crosara de Resende e Flavia Maria de Paiva Vital / Brasília: Secretaria Especial dos Direitos Humanos, 2008. Disponível em: <https:// www.governoeletronico.gov.br/documentos-e-arquivos/A\%20Convencao $\% 20$ sobre\%20os\%20Direitos\%20das\%20Pessoas\%20com\%20Deficiencia\%20Comentada.pdf> Acesso em: 19 nov. 2016.

GARCIA, Vinicius Gaspar. As pessoas com deficiência na história do Brasil. 2011. Disponível em: <http://www.bengalalegal.com/pcd-brasil> Acesso em: 18 nov. 2016.

GUGEL, Maria Aparecida. A pessoa com deficiência e sua relação com a história da humanidade. Disponível em: < http://www.ampid.org.br/ampid/Artigos/PD_Historia.php $>$ Acesso em 9 nov. 2016.

LOPES, Gustavo Casimiro. O preconceito contra o deficiente ao longo da história. EFDeportes.com, Revista Digital, Buenos Aires, ano 17, n. 176, Janeiro. 2013. Disponível em: <http:// www.efdeportes.com/efd176/o-deficiente-ao-longo-da-historia.htm> Acesso em: 9 nov. 2016.

MAIOR, Izabel. Breve trajetória histórica do movimento das pessoas com deficiência. Disponível em: <http://violenciaedeficiencia.sedpcd.sp. gov.br/pdf/textosApoio/Texto2.pdf > Acesso em: 19 nov. 2016.

RAMOS, André de Carvalho. Curso de Direitos Humanos. 4. ed., São Paulo: Saraiva, 2017.

SANTOS, Wederson R. dos. Pessoas com deficiência: nossa maior minoria. Physis: Revista de Saúde Coletiva. Rio de Janeiro, v. 18, n. 3, 2008. Disponível em: <http://dx.doi.org/10.1590/ S0103-73312008000300008> Acesso em 19 nov. 2016.

SASSAKI, Romeu Kazumi. Inclusão: construindo uma sociedade para todos. 7.ed. Rio de Janeiro: WVA, 2006.

. Nada sobre nós sem nós: Da integração à inclusão, 2011. Disponível em: <http:// www.bengalalegal.com/nada-sobre-nos> Acesso em 24 nov. 2016. 
SILVA, Otto Marques da. A epopéia ignorada - A pessoa deficiente na história do mundo de ontem e de hoje. São Paulo: CEDAS - Centro São Camilo de Desenvolvimento em Administração da Saúde, 1987.

WERNECK, Cláudia. Modelo médico x Modelo social da deficiência. In: MANUAL DA MÍDIA LEGAL 3: comunicadores pela saúde / Escola de Gente - Rio de Janeiro: WVA Editora, 2004.

2000.

. Ninguém mais vai ser bonzinho na sociedade inclusiva. 2 ed., Rio de Janeiro: WVA, 